\title{
Protection against highly pathogenic SIV by BCG-SIV recombinant priming and attenuated replicating vaccinia-SIV recombinant boosting
}

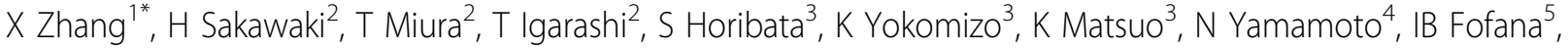 \\ W Johnson ${ }^{5}$, T Ohashi ${ }^{1}, \mathrm{H}$ Shida ${ }^{1}$
}

From AIDS Vaccine 2012

Boston, MA, USA. 9-12 September 2012

\section{Background}

We constructed recombinants of the Japanese-licensed Tokyo 172 strain of BCG and the replication-competent vaccinia virus strain $\mathrm{LC} 16 \mathrm{~m} 8 \Delta(\mathrm{m} 8 \Delta)$ (a genetically stable variant of Japanese licensed smallpox vaccine $\mathrm{LC} 16 \mathrm{~m} 8$ ) to express SIV genes. We then evaluated the protective efficacy of these recombinants against challenge with pathogenic, neutralization resistant SIVmac251.

\section{Methods}

Indian rhesus macaques were immunized with rBCG-SIV expressing SIV Gag, Env, or Rev-Tat-Nef (RTN) fusion proteins via subcutaneous injection, followed with two boosts with the Gag-, Env-, RT-, or RTN-expressing m8 $\Delta$ by skin scarification. Eight weeks after the 2nd boost, macaques were challenged up to 5 times with a low dose of SIVmac251 by the rectal route. Cellular and humoral immune responses were analyzed by standard methods. Plasma SIV RNA and cell-associated SIV proviral DNA in peripheral blood and various tissues were monitored by quantitative PCR.

\section{Results}

Env binding antibodies were elicited at similar levels in all vaccinated macaques after $m 8 \Delta$ boost, but neutralizing $\mathrm{Ab}$ against SIVmac239 was not detected. Robust SIV-specific CD4+ and CD8+ effecter memory $\mathrm{T}$ cell responses were elicited and maintained at high level until SIV challenge. One vaccinated animal had potent $\mathrm{CD} 8+\mathrm{T}$ cells that suppressed SIVmac239 replication in vitro. Plasma viraemia was not detected in this animal, even after $\mathrm{CD} 8+\mathrm{T}$ cell depletion throughout the follow-up period. Protection was confirmed by lack of detectable cell-associated provirus in various organs. A second vaccinated monkey became infected, but viral load remained from one to two logs lower than control monkeys.

\section{Conclusion}

Vaccine-induced SIV specific T cell responses appear to be effective against SIV challenge. Importantly, our results suggest that a vaccine regimen based on an rBCG prime and vaccinia $\mathrm{m} 8 \Delta$ boost (both liscensed vaccine platforms with a long track record of safety in humans) should be explored as a safe and valuable means for efficacious HIV/ AIDS vaccine.

\section{Author details}

${ }^{1}$ Institute for Genetic Medicine, Hokkaido University, Sapporo, Japan. ${ }^{2}$ Institute for Virus Research, Kyoto University, Kyoto, Japan. ${ }^{3}$ Japan BCG Laboratory, Tokyo, Japan. ${ }^{4}$ National University of Singapore, Japan. ${ }^{5}$ NEPRC, Harvard Medical School; Boston College, Boston, USA.

Published: 13 September 2012

\section{doi:10.1186/1742-4690-9-S2-P39}

Cite this article as: Zhang et al:: Protection against highly pathogenic SIV by BCG-SIV recombinant priming and attenuated replicating vaccinia-SIV recombinant boosting. Retrovirology 2012 9(Suppl 2):P39.

${ }^{1}$ Institute for Genetic Medicine, Hokkaido University, Sapporo, Japan

Full list of author information is available at the end of the article

(c) 2012 Zhang et al; licensee BioMed Central Ltd. This is an Open Access article distributed under the terms of the Creative Commons Attribution License (http://creativecommons.org/licenses/by/2.0), which permits unrestricted use, distribution, and reproduction in any medium, provided the original work is properly cited. 